\title{
Optimisation of honing process parameters for reducing surface roughness and power consumption on grey cast iron (FG-260I)
}

\section{Umesh Kumar Vates*, Shubham Sharma and Varinder Kumar Mittal}

Department of Mechanical Engineering, Amity School of Engineering and Technology, Amity University, Uttar Pradesh, Noida - 201313, India

Email: ukvates@amity.edu

Email: ssharma32@amity.edu

Email: vkmittal@amity.edu

*Corresponding author

\begin{abstract}
Optimisation of cylinder liner surface characteristics is being done in honing process for (FG-260I) grey cast iron. Response surface methodology (RSM) and design of experiment (L54) has been used with six input variables to conduct the experiments. The parameters influencing the surface finish and corresponding power consumptions were selected on the basis of available extent literature. Second order RSM approach has been applied to develop a suitable model in honing process having six inputs and single output parameters $\left(R_{a}\right)$. The significant effect of input parameters on surface roughness with corresponding power consumptions has been analysed using combined effort of RSM modelling and analysis of variance (ANOVA). The RSM modelling for the honing process on FG-260I gives significant correlation coefficient $\left(\mathrm{R}^{2}\right)$ of $96.7 \%$ and adjusted correlation coefficient $\left(\mathrm{R}_{\mathrm{adj}}\right)^{2} 96.5 \%$. The minimum surface roughness has been found by optimal parametric combinations using root mean square error (RMSE) approach. The optimised process parameters will yield acceptable surface finish at least power consumption.
\end{abstract}

Keywords: honing process; surface finish; FG-260I; response surface methodology; RSM; analysis of variance; ANOVA; root mean square error; RMSE.

Reference to this paper should be made as follows: Vates, U.K., Sharma, S. and Mittal, V.K. (2017) 'Optimisation of honing process parameters for reducing surface roughness and power consumption on grey cast iron (FG-260I)', Int. J. Additive and Subtractive Materials Manufacturing, Vol. 1, No. 1 , pp.67-81.

Biographical notes: Umesh Kumar Vates is an Assistant Professor in the Department of Mechanical Engineering, Amity School of Engineering and Technology, Amity University Uttar Pradesh (AUUP), Noida, India. $\mathrm{He}$ received his $\mathrm{PhD}$ from IIT Dhanbad, India. He has teaching, research and industrial experience of 12 years in the area of modern manufacturing. He has published more than 28 research articles in international journals and various national/international conferences in India. He is currently guiding two $\mathrm{PhD}$ scholars in manufacturing area. 
Shubham Sharma is working as an Assistant Professor-II in the Department of Mechanical Engineering, Amity School of Engineering and Technology, Amity University Uttar Pradesh (AUUP), Noida, India. He has teaching, research, industrial and administrative experience of eight years. He has published more than ten research articles in international journals and various national/international conferences of reputes. Also he has filled two national patents in the area of thermal energy efficiency. He is currently pursuing $\mathrm{PhD}$ in the field of thermal and solar energy.

Varinder Kumar Mittal is an Associate Professor in the Department of Mechanical Engineering, Amity School of Engineering and Technology, Amity University Uttar Pradesh (AUUP), Noida, India. He has teaching, research and administrative experience of 13 years in addition to core industrial experience of two years in manufacturing industry. He has published 16 research articles in international journals of repute, four book chapters in Springer books, in addition to more than 20 papers in various national/international conferences in India. He is currently guiding four $\mathrm{PhD}$ scholars.

\section{Introduction}

Honing is an important fine finishing machining process, often, used for internal cylindrical surfaces such as gun barrels, hydraulic cylinders, bearings and engine cylinder bores. Excess material is removed by means of slow moving abrasive sticks pressed against the surface to be machined. Two kind of motions namely rotational and reciprocating are imparted by the honing machine to the hone (or honing tool) carrying the abrasive sticks. Honing is a fine finishing operation, designed to remove surface flaws such as indentations, tapering, out-of-roundness, bowing, etc. Therefore not much material is removed from the component. The machining depth is limited to just a few microns. Suitable cutting fluids (coolants) are used during the honing process to resist the thermal distortion of the work piece. The chips produced during honing are larger than those produced during grinding, because the abrasive grains are in contact with the work piece for the major portion of the stroke. Bartarya and Choudhury (2002) studied the effect of cutting parameters on cutting force and surface roughness during super finishing of hard steel. The cutting speed and feed have to be carefully selected to ensure self dressing action on the abrasive sticks and to avoid their glazing. Surface quality is crucial to the performance of mating parts which have to move relative to each other during service conditions. Examples of such components include connecting rods, piston pins, shafts, bearings and engine cylinders. The automobile industry alone needs such components in ever large numbers. Traditional centre line average $R_{a}$ has been commonly used to measure the surface quality. However, recent studies have shown that specification of a single $R_{a}$ value is inadequate to completely characterise the complex surface roughness profile, especially, when questions such as contact area, contact mechanics, lubricant retention, and wear become important (Malburg and Raja, 1993; Bernados and Vosniako, 2002). Many attempts that have been made to develop a variety of techniques for surface finishing through diverse machining processes and many attempts to model the processes and optimise the process parameters. It was analysed the effect of cutting conditions and tool geometry on surface roughness by regression analysis (Allen and Man, 1982; Wang and Chang, 2004). 
Surface roughness models were built using response surface methodology (RSM) and experimental results. This method propagates the error information at the output units back to the hidden units using a generalised delta rule (Montgomery, 1991). Artificial neural network (ANN) usually requires very bulk experimental data to train and validate the models (Rumelhart and McClelland, 1986). It was analysed the power expenditure and the surface roughness of the work piece during external cylindrical grinding of a hardened steel part using RSM, which requires only few experimental data (Kwak et al., 2005). A grinding wheel of diameter $320 \mathrm{~mm}$ and width $38 \mathrm{~mm}$ was used for conducting experiments on chrome-molybdenum steel which was heat-treated to $R_{c} 60$. The factors considered as affecting the power output and surface finish included rotational speed of the work piece (rpm), depth of cut $(\mu \mathrm{m})$, and the traverse speed $(\mathrm{m} / \mathrm{min})$. RSM is being concluded as the best suited modelling tool applicable for the honing of cylinder liner. The surfaces finish analysis is also a big issue in the process optimisation of honing of cylinder liner (Staut, 1984). It has reviewed the prediction of surface roughness in machining processes (Bernados and Vosniako, 2003). They discussed the different methodologies and a strategy usually adopted to predict the surface roughness in different machining processes, based on their study, the atomic force microscopy (AFM) is one of the best suitable instruments through which very precised values (nanometres level) of surface finish is calculated among the different techniques used to surface finish measurements.

Figure 1 Honing head with tooling (see online version for colours)
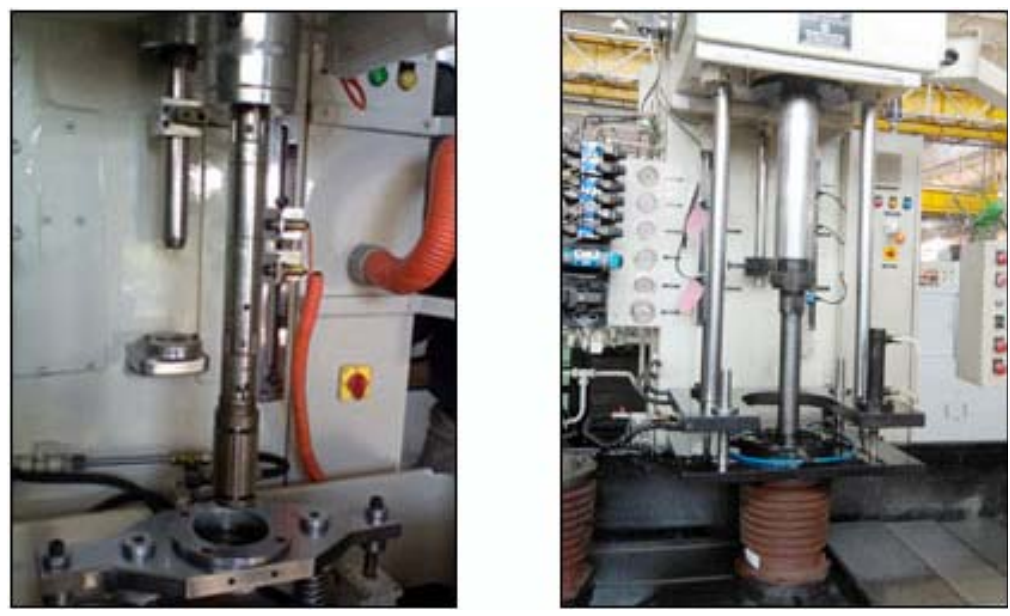

Honing process performed on FG-260I (grey cost iron) bike cylinder liner using L54 array RSM design of experiment having six input variables. The suitable surface finish and corresponding power consumptions influencing parameters were selected on the basis of available literature. Second order RSM extant or extent technique has been used to generate the models. Second order RSM has been used for surface finish modelling where independent process variables are: fluid pressure, temperature of honing environment, grit size, hone angle, circumferential speed and honing time. The optimum process parameters are essential to achieve better surface finish with adequate power consumption per unit time (watt). A lot of research techniques have been reported for response optimisation but present work uses the sum of root mean square error (SRMSE) 
approach and has achieved an improvement of more than $39.4 \%$ in surface smoothness under honing process. The concept of honing machine and setup is illustrated in Figure 1. In the rest of the paper, section provides the experimental setup followed by experimental investigation. Results and discussion are provided in Section 4 and concluded in Section 5. The paper ends with references.

\section{Experimental setup}

\subsection{Selection of parameters and work piece materials}

In the present investigation, the honing experiments have been conducted on $56 \mathrm{~mm}$ diameter of Yamaha motorcycles cylinder liner. FG-260I (grey cast iron) is used as the material of construction of the cylinder liner. Work piece material was normalised and shot blasted. The chemical composition of the work piece material is: $\mathrm{C}$ (3.14), Mn (0.62), Cr (0.22), Ni (0.05), Mo (0.13), S (0.06), P (0.49) and Si (2.1) percentage wise respectively.

Figure $2 \mathrm{R}_{\mathrm{a}}$ measurement of FG-260I by AFM (see online version for colours)

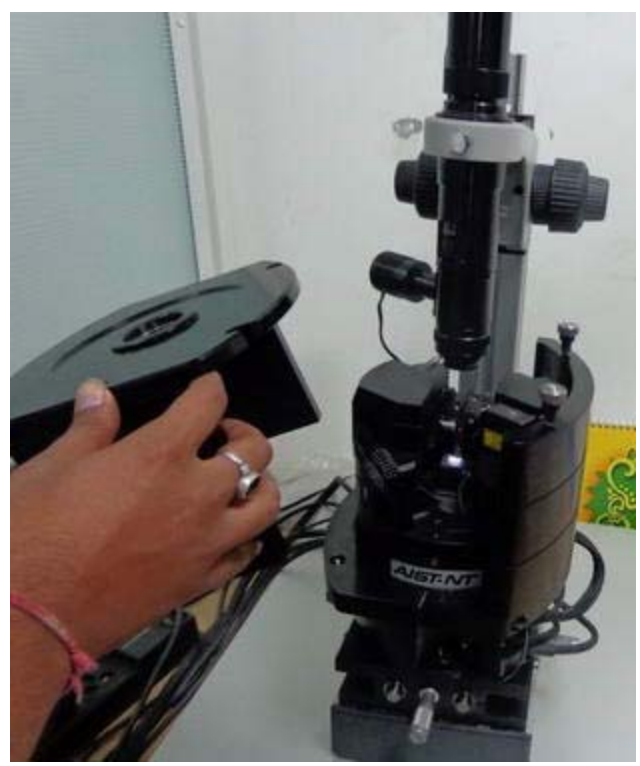

The experiments are being run on a CNC operated honing machine, model HONSD, SL NO-210, (F: 08: 0023: 02) having the facilities to hold the work piece within the place provided by the help of a fixture. Present experiments are aimed at considering significant effects of several controllable and independent parameters on surface roughness of FG-260I during honing. The requirement of surface finish and power consumption are the key factors while selecting a particular combination of input factors. Coarse grits remove high stock of material and are suitable for rough honing (A.E. Goetze GmBH, 1993). Table 1 shows the relationship between grit number and grit particle size (Boothryod and Knight, 1989). Apart from controllable and independent variables (Table 2), there are many parameters which are kept constant as mentioned in 
Table 3. Experiments have been carried out randomly using suitable Table 4, so that the repetitions of the runs are not done throughout. AFM is used for surface finish measurement which is having least count of $1 \mathrm{~nm}$.

Table 1 Grit size $(\mu \mathrm{m})$ and corresponding grit numbers

\begin{tabular}{lccccccccc}
\hline Grit no. & 36 & 54 & 80 & 120 & 220 & 320 & 400 & 500 & 600 \\
Size $(\mu \mathrm{m})$ & 710 & 430 & 266 & 142 & 66 & 32 & 23 & 16 & 8 \\
\hline
\end{tabular}

Table 2 DOE - levels of the variables

\begin{tabular}{lcccccc}
\hline $\begin{array}{l}\text { Factor } \\
\text { level }\end{array}$ & $\begin{array}{c}\text { Grit size } \\
(\mu \mathrm{m})\end{array}$ & $\begin{array}{c}\text { Temperature } \\
\left({ }^{\circ} \mathrm{C}\right)\end{array}$ & $\begin{array}{c}\text { Speed } \\
(\mathrm{rpm})\end{array}$ & $\begin{array}{c}\text { Hone angle } \\
\theta_{H}(\text { degree })\end{array}$ & $\begin{array}{c}\text { Flushing fluid } \\
\text { pressure, } P_{F}\end{array}$ & $\begin{array}{c}\text { Time } \\
\text { (in seconds) }\end{array}$ \\
\hline & & & & & bar & \\
1 & 30.5 & -5 & 300 & 0 & 1.5 & 15 \\
2 & 43 & 10 & 600 & 20 & 4.0 & 30 \\
3 & 55.5 & 25 & 900 & 40 & 6.5 & 45 \\
4 & 68 & 40 & 1,200 & 60 & 9.0 & 60 \\
5 & 80.5 & 55 & 1,500 & 80 & 11.5 & 75 \\
\hline
\end{tabular}

Table 3 Constant factors during honing

\begin{tabular}{lc}
\hline Factors & Constant values (coded) \\
\hline Jog feed & 2 \\
Low jog & 7 \\
Linear speed & 4 \\
Sensitivity & 6 \\
\hline
\end{tabular}

Table 4 Experimental observation: FG 260I - second set of readings

\begin{tabular}{cccccccccc}
\hline SL & $\begin{array}{c}\text { Grit } \\
\text { size } \\
(\mu \mathrm{m})\end{array}$ & $\begin{array}{c}\text { Environmental } \\
\text { temp. }\left({ }^{\circ} \mathrm{C}\right)\end{array}$ & $\begin{array}{c}\text { Rotational } \\
\text { speed } \\
(\text { RPM })\end{array}$ & $\begin{array}{c}\text { Hone } \\
\text { angle } \\
(\text { deg. })\end{array}$ & $\begin{array}{c}\text { Fluid } \\
\text { pressure } \\
\text { (bar) }\end{array}$ & $\begin{array}{c}\text { Honing } \\
\text { time } \\
(\text { sec. })\end{array}$ & $\begin{array}{c}\text { Ra } \\
(\mathrm{nm}) \\
\text { obs. }\end{array}$ & $\begin{array}{c}\text { Ra } \\
(\mathrm{nm}) \\
\text { pred. }\end{array}$ & $\begin{array}{c}\text { Power } \\
(\text { watt })\end{array}$ \\
\hline 1 & 43 & 40 & 600 & 60 & 9 & 60 & 371 & 363.991294 & 2.1 \\
2 & 68 & 10 & 600 & 20 & 4 & 60 & 500 & 503.786731 & 3.9 \\
3 & 68 & 10 & 600 & 20 & 9 & 30 & 555 & 565.286731 & 4 \\
4 & 43 & 10 & 1,200 & 60 & 4 & 30 & 323 & 268.134349 & 1.8 \\
5 & 68 & 10 & 600 & 60 & 4 & 30 & 452 & 487.423891 & 3.2 \\
6 & 43 & 10 & 600 & 20 & 4 & 30 & 489 & 491.929804 & 2 \\
7 & 43 & 40 & 1,200 & 20 & 4 & 30 & 338 & 354.739719 & 2.5 \\
8 & 55.5 & 25 & 900 & 40 & 6.5 & 45 & 414 & 421.360586 & 3.4 \\
9 & 55.5 & 25 & 900 & 40 & 6.5 & 45 & 404 & 421.360586 & 3.4 \\
10 & 55.5 & 25 & 900 & 40 & 6.5 & 45 & 419 & 421.360586 & 3.3 \\
11 & 68 & 40 & 600 & 60 & 4 & 60 & 548 & 471.081021 & 4.2 \\
12 & 68 & 10 & 1,200 & 20 & 4 & 30 & 489 & 512.748425 & 3.3 \\
13 & 68 & 10 & 1,200 & 60 & 9 & 30 & 451 & 454.786731 & 3.6 \\
14 & 68 & 10 & 1,200 & 20 & 9 & 60 & 538 & 537.953595 & 4.1 \\
15 & 43 & 40 & 1,200 & 20 & 9 & 60 & 325 & 289.529703 & 2.5 \\
\hline
\end{tabular}


Table 4 Experimental observation: FG 260I - second set of readings (continued)

\begin{tabular}{|c|c|c|c|c|c|c|c|c|c|}
\hline$S L$ & $\begin{array}{l}\text { Grit } \\
\text { size } \\
(\mu m)\end{array}$ & $\begin{array}{c}\text { Environmental } \\
\text { temp. }\left({ }^{\circ} \mathrm{C}\right)\end{array}$ & $\begin{array}{c}\text { Rotational } \\
\text { speed } \\
\text { (RPM) }\end{array}$ & $\begin{array}{l}\text { Hone } \\
\text { angle } \\
\text { (deg.) }\end{array}$ & $\begin{array}{l}\text { Fluid } \\
\text { pressure } \\
\text { (bar) }\end{array}$ & $\begin{array}{l}\text { Honing } \\
\text { time } \\
\text { (sec.) }\end{array}$ & $\begin{array}{l}R a \\
(n m) \\
o b s .\end{array}$ & $\begin{array}{l}\text { Ra } \\
\text { (nm) } \\
\text { pred. }\end{array}$ & $\begin{array}{l}\text { Power } \\
\text { (watt) }\end{array}$ \\
\hline 16 & 68 & 40 & 600 & 20 & 4 & 30 & 401 & 452.811466 & 3.6 \\
\hline 17 & 68 & 40 & 1,200 & 60 & 9 & 60 & 566 & 584.493291 & 4.6 \\
\hline 18 & 43 & 10 & 1,200 & 60 & 9 & 60 & 344 & 300.76636 & 2.9 \\
\hline 19 & 68 & 10 & 1,200 & 60 & 4 & 60 & 426 & 436.286731 & 3.1 \\
\hline 20 & 55.5 & 25 & 900 & 40 & 6.5 & 45 & 389 & 421.360586 & 2.6 \\
\hline 21 & 68 & 40 & 600 & 60 & 9 & 30 & 570 & 528.899203 & 4.3 \\
\hline 22 & 55.5 & 25 & 900 & 40 & 6.5 & 45 & 398 & 421.360586 & 3.2 \\
\hline 23 & 68 & 40 & 1,200 & 20 & 9 & 30 & 586 & 598.723736 & 3.8 \\
\hline 24 & 55.5 & 25 & 900 & 40 & 6.5 & 45 & 409 & 421.360586 & 3.2 \\
\hline 25 & 55.5 & 25 & 900 & 40 & 6.5 & 45 & 421 & 421.360586 & 3.2 \\
\hline 26 & 43 & 10 & 600 & 20 & 9 & 60 & 436 & 427.061815 & 2.3 \\
\hline 27 & 43 & 10 & 1,200 & 20 & 9 & 30 & 373 & 437.435468 & 1.9 \\
\hline 28 & 68 & 40 & 600 & 20 & 4 & 60 & 375 & 405.073469 & 3.7 \\
\hline 29 & 68 & 40 & 600 & 20 & 9 & 30 & 465 & 516.391651 & 3.2 \\
\hline 30 & 43 & 10 & 600 & 60 & 9 & 30 & 474 & 492.397059 & 2.1 \\
\hline 31 & 43 & 10 & 600 & 60 & 9 & 60 & 401 & 434.286417 & 3.7 \\
\hline 32 & 43 & 10 & 600 & 60 & 4 & 60 & 358 & 321.760695 & 2.5 \\
\hline 33 & 68 & 40 & 1,200 & 60 & 4 & 60 & 479 & 473.800742 & 3.4 \\
\hline 34 & 43 & 10 & 1,200 & 20 & 4 & 60 & 202 & 202.799105 & 2.8 \\
\hline 35 & 55.5 & 25 & 900 & 40 & 6.5 & 45 & 384 & 421.360586 & 3.2 \\
\hline 36 & 68 & 40 & 600 & 20 & 9 & 60 & 396 & 428.516018 & 3.7 \\
\hline 37 & 68 & 40 & 1,200 & 60 & 9 & 30 & 513 & 542.118924 & 2.8 \\
\hline 38 & 68 & 40 & 600 & 60 & 4 & 30 & 379 & 445.858665 & 2.8 \\
\hline 39 & 68 & 40 & 1,200 & 20 & 4 & 60 & 491 & 476.905554 & 3 \\
\hline 40 & 68 & 40 & 1,200 & 60 & 4 & 30 & 478 & 458.288739 & 2.7 \\
\hline 41 & 55.5 & 25 & 900 & 40 & 6.5 & 15 & 611 & 591.140082 & 1 \\
\hline 42 & 55.5 & 25 & 900 & 0 & 6.5 & 45 & 689 & 633.780867 & 2.4 \\
\hline 43 & 55.5 & 25 & 1,500 & 40 & 6.5 & 45 & 310 & 362.371776 & 2.5 \\
\hline 44 & 55.5 & 55 & 900 & 40 & 6.5 & 45 & 382 & 397.015764 & 2.4 \\
\hline 45 & 55.5 & 25 & 900 & 40 & 1.5 & 45 & 268 & 332.912809 & 2.3 \\
\hline 46 & 55.5 & 25 & 900 & 40 & 6.5 & 45 & 398 & 421.360586 & 2.4 \\
\hline 47 & 30.5 & 25 & 900 & 40 & 6.5 & 45 & 175 & 241.711468 & 2.1 \\
\hline 48 & 80.5 & 25 & 900 & 40 & 6.5 & 45 & 763 & 697.009705 & 5.2 \\
\hline 49 & 55.5 & 25 & 900 & 40 & 6.5 & 45 & 412 & 421.360586 & 2.3 \\
\hline 50 & 55.5 & 25 & 900 & 80 & 6.5 & 45 & 372 & 386.940305 & 2.4 \\
\hline 51 & 55.5 & 25 & 900 & 40 & 6.5 & 75 & 337 & 363.581091 & 3.3 \\
\hline 52 & 55.5 & 25 & 300 & 40 & 6.5 & 45 & 600 & 562.349396 & 2.2 \\
\hline 53 & 55.5 & 25 & 900 & 40 & 11.5 & 45 & 523 & 509.808364 & 2.1 \\
\hline 54 & 55.5 & -5 & 900 & 40 & 6.5 & 45 & 315 & 361.705409 & 1.9 \\
\hline
\end{tabular}




\subsection{RSM algorithms}

RSM has been reported on the development of second order multiple regressions (SOMR) (Witten and Frank, 2001). It would have its own input and output characteristics, and therefore it can only be applied for modelling of some specific honing processes.

$$
\begin{aligned}
S R= & -4.7766 \theta_{\mathrm{H}}+0.05448 * \mathrm{rpm}-0.00775 * \mu \mathrm{m}-0.00538 *{ }^{\circ} \mathrm{C} \\
& +0.000671 * \text { second }-0.000947 * \text { bar }
\end{aligned}
$$

\section{Experimental investigation}

Correlation coefficient $\left(\mathrm{R}^{2}\right)$ of observed and predicted $\mathrm{R}_{\mathrm{a}}$ : the correlation between observed and predicted $R_{a}$ is very close which indicates the adequate modelling done (Figure 4). Three different models were constructed, but the second model was the best performing one than the other two which is shown plotted in Figures 3 to 5. Residual verses vs. fit plot are being given to understand the deviation from the mean values which is given in Figure 6. Figure 4 indicates the relationship between the observed and predicted correlation coefficient $\left(\mathrm{R}^{2}\right)$ is 0.967 which gives excellent result.

Figure 3 Predictions against observations of $\mathrm{R}_{\mathrm{a}}$ for model-M2-FG260I (see online version for colours)

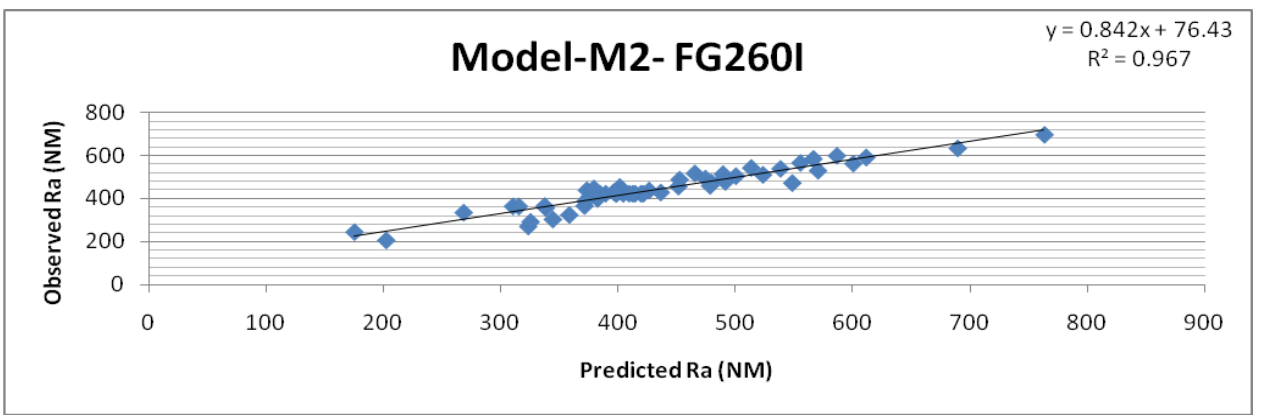

Figure 4 Predictions against observations of $\mathrm{R}_{\mathrm{a}}$ for model-M1-FG 260I (see online version for colours)

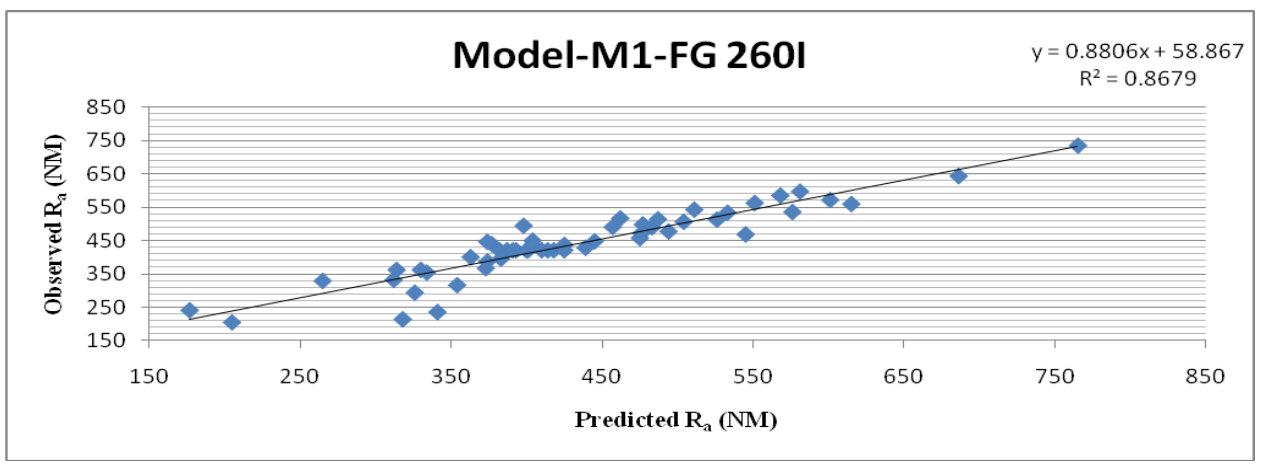


Figure 5 Predictions against observations of $R_{a}$ for model-M3-FG260I (see online version for colours)

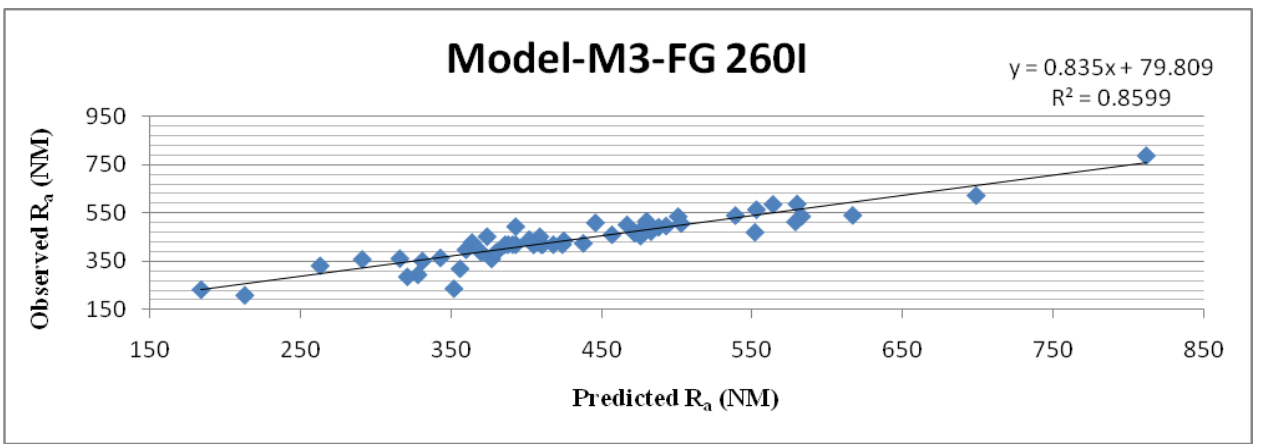

Figure 6 Residual vs. fit for $\mathrm{R}_{\mathrm{a}}$ for model-M3, FG-260I (see online version for colours)

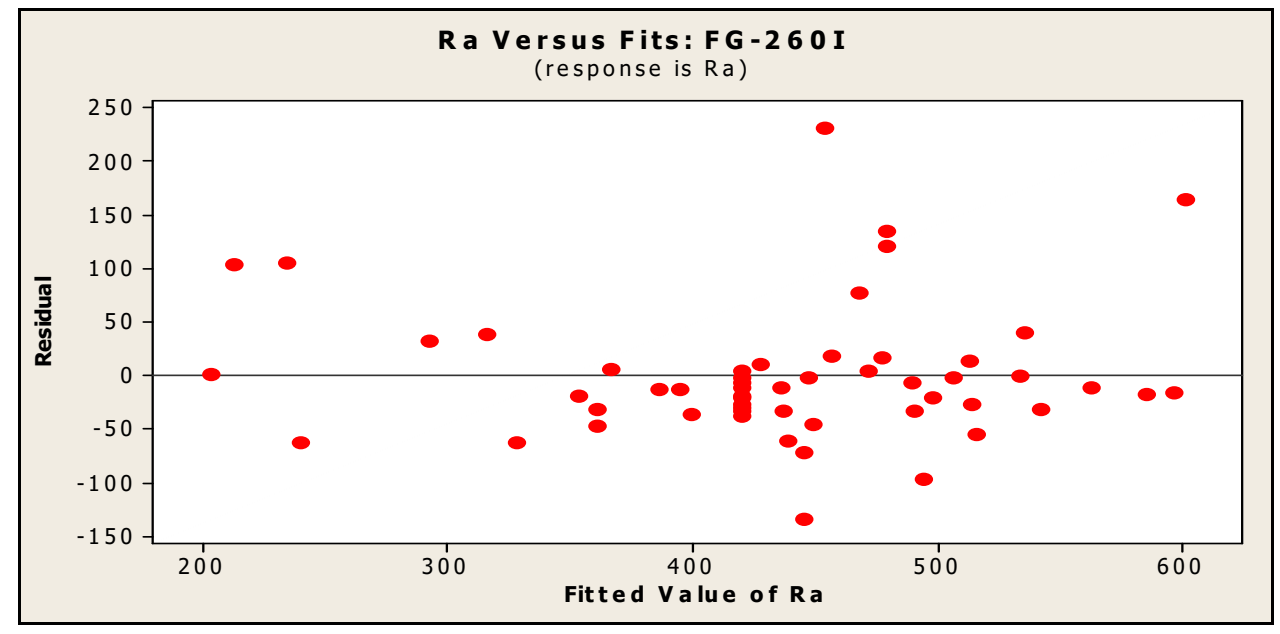

Figure 7 Probability plot of $\mathrm{R}_{\mathrm{a}}$ (pred.): FG 260I, model 2 (see online version for colours)

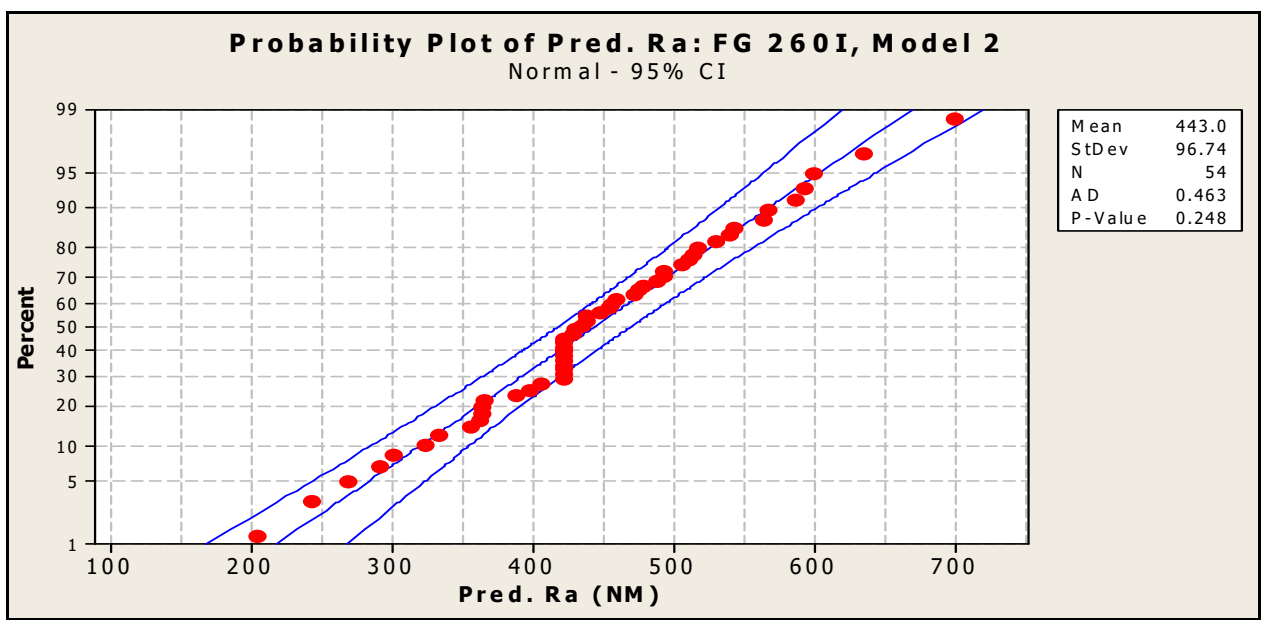


Predicted surface finish data is used to analyse the interactions of factors, interaction plots are being constructed in Figure 9 which indicate the variation of surface roughness depending on individual factors. It is also evident that the factors are found significant as per the ANOVA test at 95\% confidence level significantly as given in Figures 6 and 7 consequently. Figures 7 and 8 indicating indicate the probability plot of the predicted responses which are significant.

Figure 8 Probability plot of power cons. (watt): FG 260I, model 2 (see online version for colours)

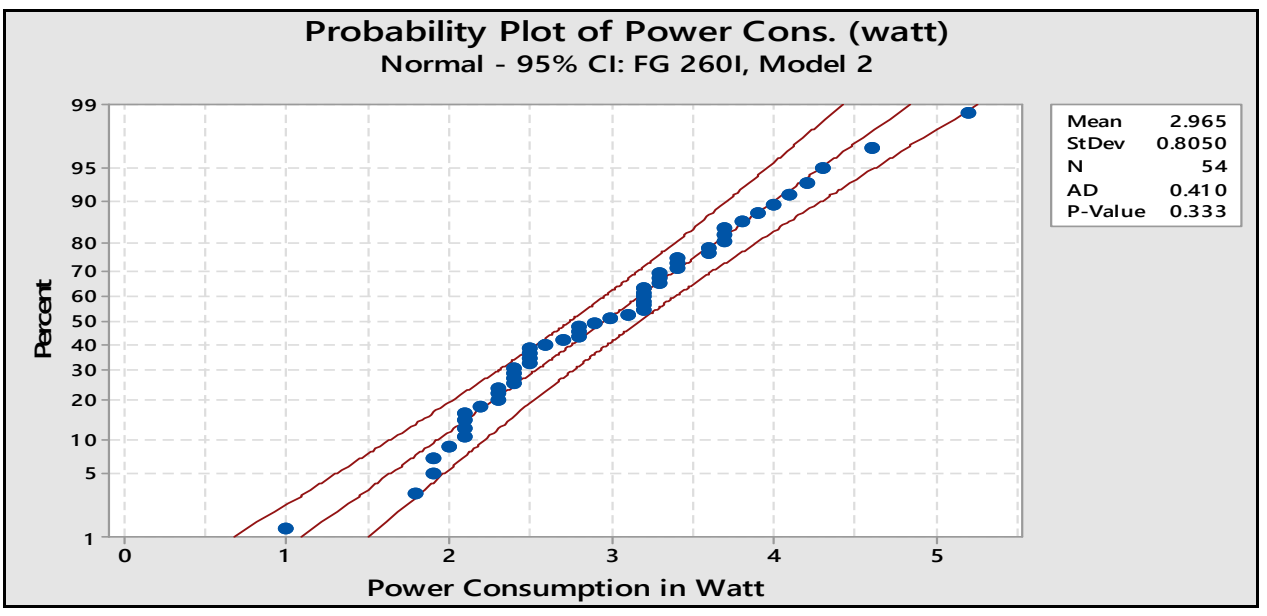

Figure 9 Individual parametric interaction plot of $\mathrm{R}_{\mathrm{a}}$ (Pred.): FG 260I, Model 2 (see online version for colours)

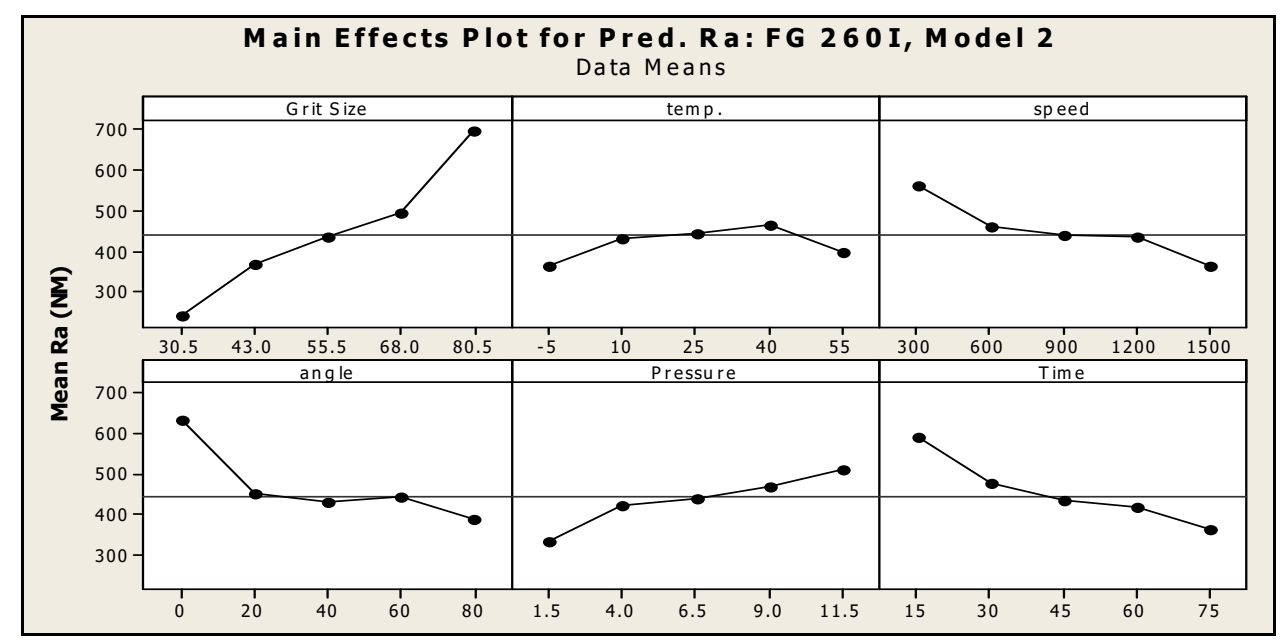

Optimisation of surface roughness is being done individually using the root mean square error approach which is indicated in Figures 10 to 15 respectively. The Minitab 16 is used to draw the figures for the optimisation. Each figure indicates the most optimal points having the minimum possible surface roughness at possible corresponding power consumption. 
Figure $103 \mathrm{D}$ plot of $\mathrm{R}_{\mathrm{a}}$ (pred.) vs. power cons. with grit size: FG 260I, model 2 (see online version for colours)

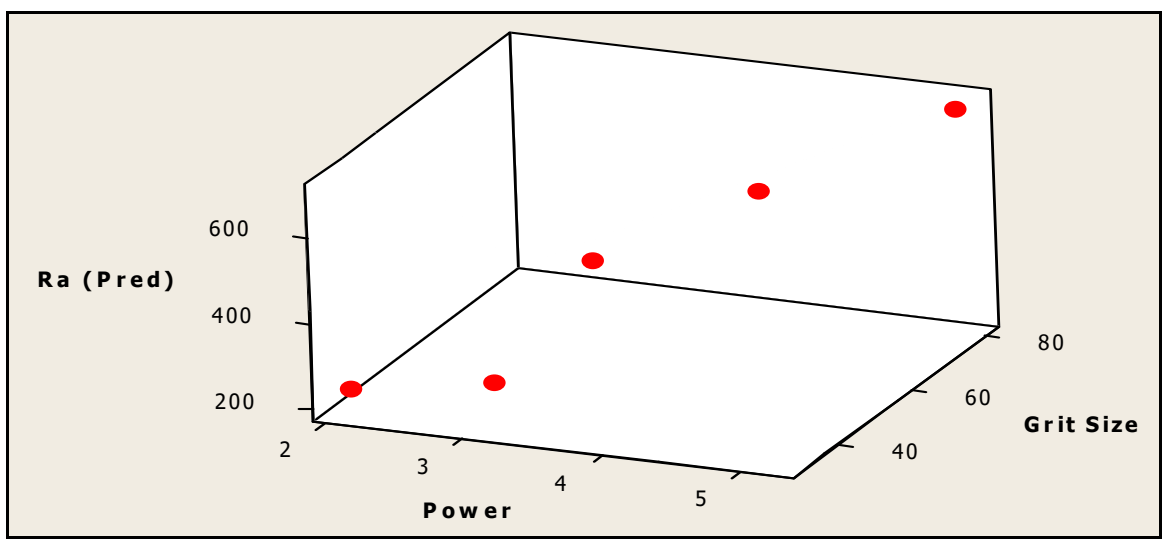

Figure 11 3D plot of $\mathrm{R}_{\mathrm{a}}$ (pred.) vs. power cons. with env. temp.: FG 260I, model 2 (see online version for colours)

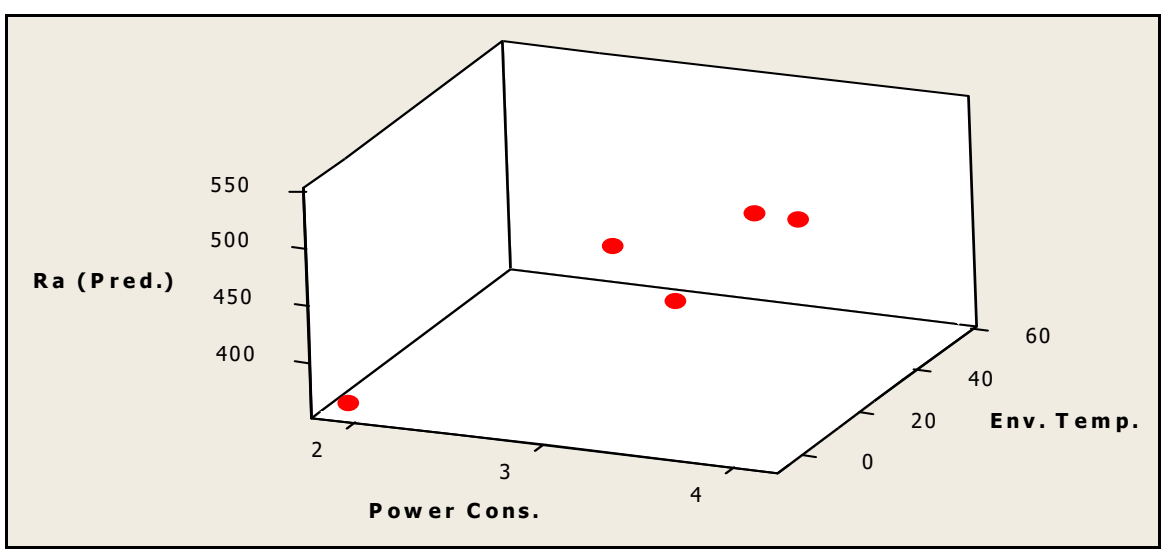

Figure 12 3D plot of $\mathrm{R}_{\mathrm{a}}$ (pred.) vs. power cons. with speed: FG 260I, model 2 (see online version for colours)

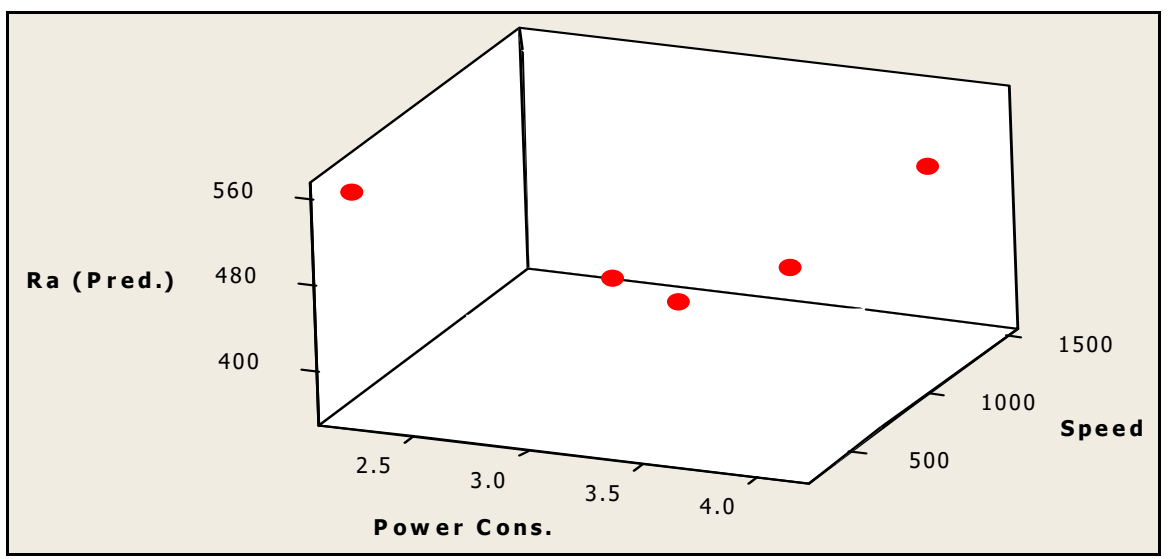


Figure 13 3D plot of $\mathrm{R}_{\mathrm{a}}$ (pred.) vs. power cons. with hone angle: FG 260I, model 2 (see online version for colours)

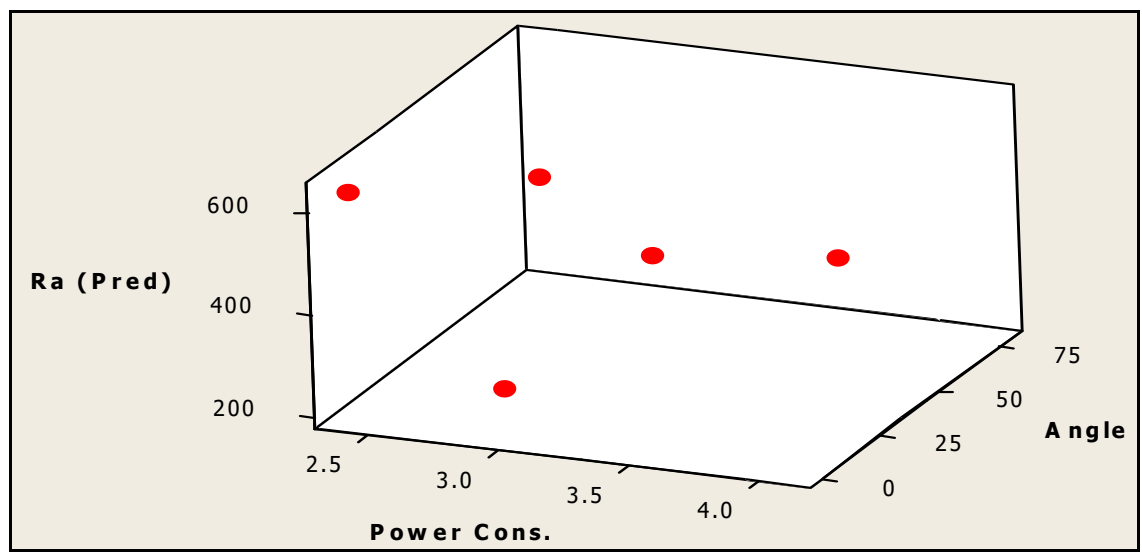

Figure 14 3D plot of $R_{a}$ (pred.) vs. power cons. with fluid pressure: FG 260I, model 2 (see online version for colours)

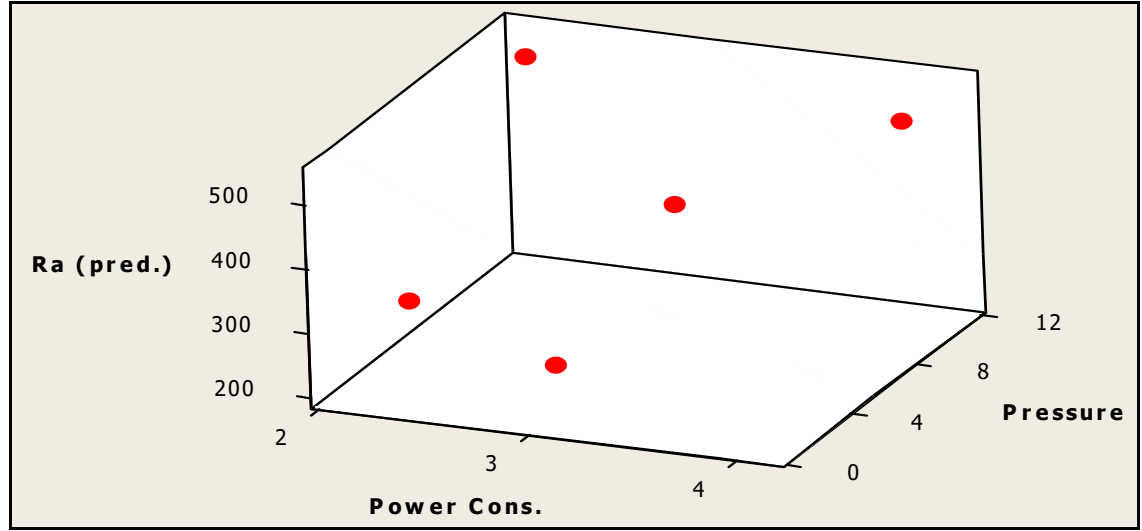

Figure $153 \mathrm{D}$ plot of $\mathrm{R}_{\mathrm{a}}$ (pred.) vs. power cons. with hone time: FG 260i, model 2 (see online version for colours)

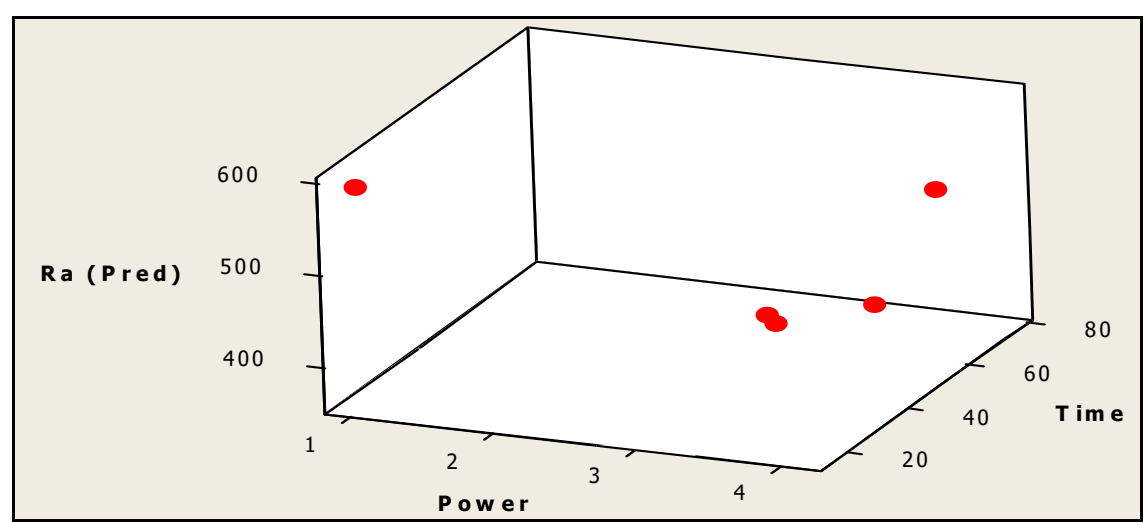


It has been indicated from RMSE manual method that the surface roughness will be optimum at the values of individual parametric combinations of grit size, environment temperature, rotational speed, hone angle, and fluid pressure, and honing time is $43,-5$, $1200,60,4$ and 75 respectively.

Table 5 indicates nested ANOVA for surface roughness and it shows that all the six input factors have significant interaction with each other. P-values of each factor indicates the best interaction in factors.

Table 5 ANOVA analysis

\begin{tabular}{lcccc}
\hline Term & Coef & SE coef & $T$ & $P$ \\
\hline Constant & $1,210.98$ & 499.631 & 2.424 & 0.021 \\
Grit size & -8.12 & 7.739 & -1.049 & 0.302 \\
Env. temp. & -10.01 & 8.535 & -1.173 & 0.250 \\
Speed & -0.48 & 0.386 & -1.246 & 0.222 \\
Hone ang. & -4.71 & 5.751 & -0.820 & 0.419 \\
Pressure & 14.76 & 42.643 & 0.346 & 0.731 \\
Time & -14.14 & 6.907 & -2.048 & 0.049 \\
Grit size * env. temp. & 0.05 & 0.090 & 0.552 & 0.585 \\
Grit size * speed & 0.01 & 0.005 & 1.401 & 0.171 \\
Grit size * hone ang. & 0.04 & 0.074 & 0.565 & 0.576 \\
Grit size * pressure & -0.25 & 0.569 & -0.448 & 0.657 \\
Grit size * time & 0.17 & 0.095 & 1.840 & 0.075 \\
Env. temp. * speed & 0.01 & 0.004 & 1.517 & 0.139 \\
Env. temp. * hone ang. & 0.03 & 0.055 & 0.556 & 0.582 \\
Env. temp. * pressure & 0.19 & 0.435 & 0.448 & 0.657 \\
Env. temp. * time & -0.02 & 0.072 & -0.316 & 0.754 \\
Speed * hone ang. & -0.00 & 0.003 & -1.114 & 0.273 \\
Speed * pressure & 0.00 & 0.020 & 0.013 & 0.990 \\
Speed * time & -0.00 & 0.003 & -0.162 & 0.872 \\
Hone ang. * pressure & 0.10 & 0.299 & 0.326 & 0.747 \\
Hone ang. * time & 0.06 & 0.050 & 1.221 & 0.231 \\
Pressure * time & 0.18 & 0.413 & 0.433 & 0.668 \\
\hline S $=81.0992 ;$ PRESS $=633,107$ & & & & \\
R-sq $=96.7 \% ;$ R-sq $($ pred $)$ & $96.5 \%$ R-sq $($ adj $)$ & $96.6 \%$ & & \\
\hline & & & & \\
\hline
\end{tabular}


Table 5 ANOVA analysis (continued)

\begin{tabular}{|c|c|c|c|c|c|c|}
\hline \multicolumn{7}{|c|}{ Analysis of variance for $R_{a}$} \\
\hline Source & $D F$ & Seq $S S$ & Adj $S S$ & $\operatorname{Adj} M S$ & $F$ & $P$ \\
\hline Regression & 21 & 423,124 & 423,124 & $20,148.8$ & 3.06 & 0.002 \\
\hline Linear & 6 & 314,556 & 54,783 & $9,130.5$ & 1.39 & 0.249 \\
\hline Grit size & 1 & 219,780 & 7,241 & $7,240.7$ & 1.10 & 0.302 \\
\hline Env. temp. & 1 & 2,463 & 9,044 & $9,044.3$ & 1.38 & 0.250 \\
\hline Speed & 1 & 17,140 & 10,203 & $10,203.2$ & 1.55 & 0.222 \\
\hline Hone ang. & 1 & 5,290 & 4,418 & $4,417.5$ & 0.67 & 0.419 \\
\hline Pressure & 1 & 53,694 & 788 & 788.4 & 0.12 & 0.731 \\
\hline Time & 1 & 16,189 & 27,581 & $27,581.3$ & 4.19 & 0.049 \\
\hline Interaction & 15 & 108,568 & 108,568 & $7,237.9$ & 1.10 & 0.394 \\
\hline Grit size $*$ env. temp. & 1 & 948 & 2,006 & $2,006.4$ & 0.31 & 0.585 \\
\hline Grit size $*$ speed & 1 & 48,245 & 12,905 & $12,904.9$ & 1.96 & 0.171 \\
\hline Grit size $*$ hone ang. & 1 & 5,851 & 2,103 & $2,103.2$ & 0.32 & 0.576 \\
\hline Grit size $*$ pressure & 1 & 568 & 1,318 & $1,318.0$ & 0.20 & 0.657 \\
\hline Grit size $*$ time & 1 & 19,180 & 22,274 & $22,273.9$ & 3.39 & 0.075 \\
\hline Env. temp. * speed & 1 & 11,036 & 15,130 & $15,130.4$ & 2.30 & 0.139 \\
\hline Env. temp. $*$ hone ang. & 1 & 3,375 & 2,031 & $2,031.1$ & 0.31 & 0.582 \\
\hline Env. temp. $*$ pressure & 1 & 1,133 & 1,319 & $1,319.1$ & 0.20 & 0.657 \\
\hline Env. temp. $*$ time & 1 & 645 & 658 & 657.8 & 0.10 & 0.754 \\
\hline Speed $*$ hone ang. & 1 & 6,520 & 8,167 & $8,167.0$ & 1.24 & 0.273 \\
\hline Speed $*$ pressure & 1 & 147 & 1 & 1.1 & 0.00 & 0.990 \\
\hline Speed $*$ time & 1 & 6 & 174 & 173.5 & 0.03 & 0.872 \\
\hline Hone ang. * pressure & 1 & 285 & 697 & 697.0 & 0.11 & 0.747 \\
\hline Hone ang. $*$ time & 1 & 9,394 & 9,798 & $9,797.7$ & 1.49 & 0.231 \\
\hline Pressure $*$ time & 1 & 1,234 & 1,234 & $1,233.8$ & 0.19 & 0.668 \\
\hline Residual error & 32 & 210,466 & 210,466 & $6,577.1$ & & \\
\hline Lack-of-fit & 23 & 209,073 & 209,073 & $9,090.1$ & 58.70 & 0.000 \\
\hline Pure error & 9 & 1,394 & 1,394 & 154.8 & & \\
\hline Total & 53 & 633,591 & & & & \\
\hline
\end{tabular}

\section{Results and discussion}

It is evident that one value from each level of input parameters corresponding to the lowest possible square of errors has been selected. 3D scattered plot were plotted (Figures 10 to 15 ) between surface roughness vs. power consumption and input factors individually. Surface roughness of FG-260I cylinder liner using honing has been investigated by setting the individual optimum parameters. The best parametric 
combination has also been also optimised, i.e., grit size, environmental temperature, rpm, hone angle, fluid pressure and honing time is $43 \mu \mathrm{m},-5$ deg., $1,200 \mathrm{rpm}, 60^{\circ}$, $4 \mathrm{~kg} / \mathrm{cm}^{2}$ and 75 seconds respectively. The observed and predicted values of surface roughness have been analysed by performing the honing process using optimised parametric combination as $R_{a}=187.3 \mathrm{~nm}$ and $R_{a}=176.48640 \mathrm{~nm}$ consequently along with corresponding power consumption $1.3 \mathrm{Jule} / \mathrm{second}$. It is very clear that RSM modelling technique is best fitted for the prediction of surface roughness and is able to successfully minimise $R_{a}$ by $39.84 \%$ from its average value of $R_{a}=442.952 \mathrm{~nm}$.

The honing processes were also performed on FG 260I using combined optimal parametric combination and average experimental surface roughness measured and given as Table 6.

Table 6 Optimisation of parameters

\begin{tabular}{lc}
\hline Material & $F G 260 I$ \\
\hline Input parametric combinations: $\mathrm{G}_{\mathrm{s}}, \mathrm{T}_{\mathrm{e}}, \mathrm{Vp}, \theta, \mathrm{P}_{\mathrm{f}}$ and $\mathrm{M}_{\mathrm{t}}$ & $43,-5,1,200,60,4$ and 75. \\
Predicted $\mathrm{R}_{\mathrm{a}}(\mathrm{nm})$ & 176.48640 \\
Experimental $\mathrm{R}_{\mathrm{a}}(\mathrm{nm})$ & 187.3 \\
Percentage error in $\mathrm{R}_{\mathrm{a}}$ & 6.126 \\
Average $\mathrm{R}_{\mathrm{a}}(\mathrm{nm})$ & 442.952 \\
Percentage optimisation of $\mathrm{R}_{\mathrm{a}}$ & $39.84 \%$ \\
$\left(\right.$ aver. $\mathrm{R}_{\mathrm{a}}-$ pred. $\left.\mathrm{R}_{\mathrm{a}}\right) /$ aver. $\mathrm{R}_{\mathrm{a}} * 100$ & \\
Corresponding power cons. $(\mathrm{W})$ & 1.3 \\
\hline
\end{tabular}

\section{Conclusions}

Honing process was done on grey cast iron (FG-260I) $100 \mathrm{cc}$ motor bike cylinder liner using semi-automatic experimental setup. RSM is a robust design of experiment and modelling techniques which requires very less number of experiments to analyse the optimum surface roughness without altering any significant change in power consumption. RSM is the most powerful approach for modelling the honing process. It is also a fact that the most significant correlation coefficient (model 2 of FG-260I) was obtained between observed and predicted values of surface roughness. Present research has used the SRMSE approach as parametric optimisation to achieve the improvement of more than $39.4 \%$ from its average prediction in surface roughness under honing process.

\section{References}

Allen, D.M. and Man, F.B. (1982) Analyzing Experimental Data by Regression, Lifetime Learning Publication, Belmont, California, USA.

Bartarya, G. and Choudhury, S.K. (2002) 'Effect of cutting parameters on cutting force and surface roughness during finish hard turning AISI52100 grade steel', Procedia CIRP, Vol. 1, pp.651-656.

Bernados, P.G. and Vosniako, G.C. (2003) 'Predicting surface roughness in machining: a review', International Journals of Machine Tools and Manufacture, Vol. 43, No. 8, pp.833-844. 
Bernados, P.G. and Vosniako, G.C. (2002) 'Predicting surface roughness in CNC face milling using neural networks and Taguchi's design of experiments', Robotics and Computer Integrated Manufacturing, Vol. 18, Nos. 5-6, pp.343-354.

Boothryod, G. and Knight, W.A. (1989) Fundamentals of Machining and Machine Tools, 2nd ed., Marcel Dekker, New York.

A.E. Goetze GmBH (1993) AE Goetze Honing Guide - Rating Criteria for the Honing of Cylinder Running Surfaces, Burscheid.

Kwak, J.S., Sim, S.B. and Jeong, Y.D. (2005) 'An analysis of grinding power and surface roughness in external cylindrical grinding of hardened SCM 440 steel using the response surface method', International Journal of Machine Tools and Manufacture, Vol. 46, Nos. 3-4, pp.304-312.

Malburg, M.C. and Raja, J. (1993) 'Characterization of surface texture generated by plateau honing process', CIRP Annals, Vol. 42, No. 1, pp.637-640.

Montgomery, D.C. (1991) Design and Analysis of Experiments, Wiley, Singapore.

Rumelhart, D.E. and McClelland, J. (1986) Parallel Distributed Processing, MIT Press, Cambridge, Mass.

Staut, K.J. (1984) 'Surface topography of cylinder bores: the relationship between manufacture characterization and function', Wear, Vol. 95, No. 2, pp.111-125.

Wang, M.Y. and Chang, H.Y. (2004) 'Experimental study of surface roughness in slot end milling', International Journal of Machine Tools and Manufacture, Vol. 44, No. 1, pp.51-57.

Witten, I.H. and Frank, E. (2001) Data Mining: Practical Machine Learning Tools \& Techniques with Java Implementations, Morgan Kaufman Publishers, San Francisco.

\section{Nomenclature}

\begin{tabular}{llll}
\hline HP & Honing of cylinder liner & $\mathrm{T}$ & Temperature \\
RSM & Response surface methodology & $\tau$ & Duty cycle \\
F & Feed & $\mathrm{T}_{\mathrm{M}}$ & Machining time \\
V & Speed & $\mathrm{R}_{\mathrm{a}}$ & Surface roughness \\
Gs & Grit size & MRR & Material removal rate \\
Gn & Grit number & MSE & Mean square error \\
Fn & Forces & AFM & Atomic force microscopy \\
Fp & Fluid pressure & Qe & Hone angle \\
\hline
\end{tabular}

